\title{
QUALIDADE NA APRECIAÇÃO MUSICAL: escuta ativa direcionada
}

\author{
Alexandre Luís Sampaio de Freitas ${ }^{1}$ \\ Ivan Costa Oliveira ${ }^{2}$ \\ Cloércio Augusto BARRA ${ }^{3}$ \\ Ana Paula Guimarães OLIVEIRA ${ }^{4}$
}

\author{
${ }^{1}$ Licenciando em Música pela UNINCOR. alexandrefreitasfeeling@ hotmail.com \\ ${ }^{2}$ Licenciando em Música pela UNINCOR. aprendizbass@yahoo.com.br \\ ${ }^{3}$ Professor do Curso de Música da UNINCOR. prof.cloercio.barra@unincor.edu.br \\ ${ }^{4}$ Professora de Artes/Música no IFTM. anapaulaguima07@yahoo.com.br
}

Recebido em: 17/09/2015 - Aprovado em: 21/05/2016 - Disponibilizado em: 30/07/2016

\begin{abstract}
Resumo:
Este trabalho relata as experiências e identificação de materiais pedagógicos, ferramentas, elementos musicais, procedimentos, dinâmicas e informações que viabilizem uma Escuta Ativa Direcionada de nível Moral e posteriormente, através do processo de ensino-aprendizagem, estimule e oriente os alunos a realizarem esta prática sozinhos, independente do gênero musical, objetivando assim a pluralidade cultural. Através de repertório selecionado por pesquisa em sala de aula e critérios didáticos foram realizados situações e procedimentos através de vivências musicais que ativassem nos alunos a paixão pela música, assim ocasionando a apreciação e musicalização com qualidade. O presente artigo relata a importância da escuta ativa para alunos que tenham aulas de educação musical e os benefícios que essa escuta proporciona através de resultados. O mesmo é direcionado não somente à profissionais de ensino de música, mas também aos que se interessarem pela temática por proporcionar meios de captação de recursos pedagógicos musicais e organização deles.
\end{abstract}

Palavras-chave: Apreciação Musical. Educação Musical. Música na Escola. Platéia Musical. História da Música. Estilos Musicais.

\begin{abstract}
:
This paper describes the experiences and identification of training materials, tools, musical elements, procedures, dynamic and information that enable one Active Listening level Directed and later, through the process of teaching and learning, encourage and guide students to undertake this practice alone, regardless of genre, so the objective of cultural diversity. Through repertoire selected for research in the classroom and educational criteria were performed situations and procedures though musical experiences that have enabled students passion for music, thus causing the appreciation and music education with quality. This article presents the importance of active listening to students who have musical education classes and the benefits that this provides listening through results. The same is directed not only to music education professionals, but also to those interested in the theme by providing capturing means of music teaching resources and their organization.
\end{abstract}

Keywords: Music Appreciation. Music Education. Music School. Musical audience. History of Music. Musical styles. 


\section{Introdução}

A escuta musical faz parte do contexto humano. Esta arte maior está presente todos os dias em quase tudo que convivemos. Todos escutam música, passiva e ativamente.

Melhor qualidade de vida agrega diversos fatores, dentre os quais citamos variedade e riqueza cultural que o indivíduo adquire em sua vida. E esta carência é ainda mais nociva à população desfavorecida na área social e cultural.

As informações e apreciações musicais são, sem dúvidas, um ponto alto nesta questão. As diferenças entre as informações retratam o nível intelectual de cada um e podem até mesmo direcionar graus de escolaridade e conhecimento da população no campo social e cultural.

Estudos científicos em diversas áreas mostram que a mídia é um veículo de informação eficaz e que pode manipular seus interesses. Nestes termos dita a moda e mascara tendências musicais investindo em má qualidade e produtos descartáveis, exercendo persuasão e controle intelectual sobre a população.

Uma das atividades que podem mudar o panorama desta persuasão é um investimento maior da atividade cultural na escola, se beneficiando da legislação que inclui a Música como uma disciplina obrigatória na rede escolar. E através da Escuta Ativa Direcionada - que é a organização da comunicação musical com seus aspectos culturais, sociais, religiosos e étnicos, para compreensão da linguagem transmitida - podemos resgatar valores e formar opiniões que favoreçam este enriquecimento.

Este trabalho investiga os métodos de pesquisa para que sejam aplicadas as técnicas de Escuta Ativa Direcionada, assim proporcionando melhor qualidade na apreciação musical.

O objetivo principal dessa técnica de escuta ativa direcionada é estimular nos alunos do ensino fundamental a vivência e entendimento indireto das questões contemplativas musicais, proporcionando enriquecimento pessoal e cultural para os mesmos.

Este trabalho não visa à interpretação e/ou compreensão teórica e criação dos elementos do processo musical, porém se houver oportunidade e viabilidade cabe ao professor de educação musical contemplar estas ações em seu ambiente de aula.

O primeiro passo foi executar uma pesquisa com questionamentos orais para os alunos, que permitisse constatar: as influências e referências musicais familiares; ambiente musical à sua volta (escola, vizinhança, igreja, entre outros); formação musical familiar (músicos na família); preferências musicais (estilos, gêneros, épocas e artistas). 
Em seguida, realizou-se uma análise das informações obtidas, resultando em uma média para escolher as melhores opções para integrar o presente trabalho, levando em consideração as diversidades culturais e novas tendências musicais presentes na mídia nacional. Acrescentou-se ao repertório escolhido um material musical diferente para contemplar uma variedade de estilos, gêneros, épocas e artistas. Com esta forma procurou-se equilibrar, diversificar e contemplar os elementos necessários para a aplicação desta proposta de Escuta Ativa Direcionada, seguindo as orientações da Lei de Diretrizes e Bases da Educação Nacional de trabalhar a variedade e a diversidade cultural existente no Brasil.

O próximo passo foi realizar uma pesquisa e uma classificação individual dos elementos constantes no objeto de pesquisa, tais como: história e desenvolvimento do estilo ou gênero musical (regiões, finalidades, principais artistas difusores, épocas, evoluções, entre outros); instrumentos musicais mais utilizados; exposição e análise dos elementos e arranjos musicais; interpretação cultural do texto (finalidades e objetivos do autor); curiosidades sobre o autor ou composição (versões alternativas da obra, histórico de acontecimentos e fatos que envolveram o processo de composição, entre outros).

No último passo o professor apresentou o material - fruto da pesquisa citada anteriormente - aos alunos na sala de aula. Utilizou estratégias de ensino e recursos didáticos (equipamentos de som) para que os alunos pudessem ouvir as canções e expôs os elementos pesquisados e elencados de cada obra. Depois seguiu instigando o senso crítico e criativo dos mesmos, abrindo espaço para questionamentos, observações e debates. Procurou-se estabelecer um padrão de uma obra trabalhada por aula, para que se pudesse tirar maior proveito do conteúdo e maior fixação do mesmo pelos alunos, desenvolvendo de forma efetiva o trabalho de Escuta Ativa Direcionada e propiciando uma avaliação concreta e efetiva de cada aluno.

\section{Considerando os Parâmetros}

Curriculares Nacionais publicados em 1997, no seu sexto volume contemplando Artes, encontra-se a organização dos conteúdos escolares em "áreas de conhecimento", baseados em três eixos norteadores: produção, fruição e reflexão. Estes eixos buscam a pluralidade cultural, e em Música, conteúdos que devem ser trabalhados como produto cultural e histórico.

Justifica-se, portanto, o uso da Escuta Ativa Direcionada que o tema aqui propõe, como uma atividade importantíssima no processo didático-pedagógico a ser desenvolvido na Educação Musical junto às escolas regulares. 


\section{Materiais e Métodos}

Para a realização do referente trabalho, desenvolveu-se uma pesquisa qualitativa com revisão bibliográfica e dados obtidos através de pesquisa de campo feita na Escola Municipal Professora Aparecida Machado Guedes de Oliveira Cruz, na turma do $5^{\mathrm{a}}$ Ano do Ensino Fundamental II da cidade de Lorena - SP. O presente trabalho tem como principal objetivo identificar a participação dos alunos no processo de ensinoaprendizagem musical e as práticas pedagógicas dos docentes; investigar os recursos didáticos disponibilizados pela escola e os professores; e auxiliar profissionais do ensino de música com estratégias complementares com a possibilidade de utilização em sala de aula.

O ensino de música contribui de forma positiva e significativa à aprendizagem do aluno nas outras unidades curriculares da educação básica de ensino, o que constata uma pesquisa feita pelo Departamento de Psiquiatria da Universidade Federal de São Paulo, com crianças da rede pública de educação, de que a música possui capacidade de auxiliar no desenvolvimento escolar (GOULART, 2013).

O ensino deve ser voltado de acordo com a realidade do aluno levando em consideração as diferenças regionais e sociais, valorizando e conhecendo a "pluralidade do patrimônio sócio cultural brasileiro, bem como aspectos socioculturais de outros povos e nações, posicionando-se contra qualquer discriminação baseada em diferenças culturais, de classe social, de crenças, de sexo, de etnia ou outras características individuais e sociais" (Parâmetros Curriculares Nacionais Arte, 1997).

Entende-se que, no ensino de música, o professor deve ser mediador de conhecimentos e proporcionar meios para uma escuta e participação ativa do aluno nas aulas, e para que isso ocorra é preciso utilizar estratégias e recursos didáticos adequados ao plano de aula. SILVA NETO (2012), trata o ouvir como ferramenta didática para o professor e ressalta a importância da utilização desse recurso para se obter uma "escuta musical ativa". Com o avanço das Tecnologias de Informação é possível agregar novos recursos para as aulas proporcionando um ensino diferenciado e atraente para o discente.

Maria da Glória da Silva Barbosa realizou uma pesquisa onde pode-se constatar “a importância de se formar platéia em música, visando a uma escuta musical autônoma, crítica e consciente" (BARBOZA, 2011. p.9). Analisando esse aspecto pode-se dizer que o professor tem um papel fundamental e insubstituível na formação do aluno e pode influenciar no gosto musical e na própria qualidade da escuta musical do mesmo.

Entende-se que envolvendo a teoria, a prática e o contexto no ensino de música, é 
possível obter um ensino de forma eficiente e completo, gerando resultados positivos no processo ensino-aprendizagem.

Esta pesquisa visa direcionar e auxiliar profissionais de ensino no campo de atuação como professor de música para que o mesmo desperte no aluno o gosto pelo estudo de música; ressaltar a importância da apreciação musical com apuro sensível; e despertar o interesse em outras pessoas sobre o referido tema.

\section{Escuta Ativa Direcionada: Nível Moral}

De acordo com MOLINA (2012), a audição musical pode ser organizada em quatro níveis: literal, moral, analógico e anagógico.

Nesta metodologia de pesquisa objetivamos o nível de escuta ativa moral com direcionamento. Entre os recursos metodológicos e materiais de apoio utilizados para esta prática estavam quadro negro, impressos e aparelho de som.

A atividade para realização e desenvolvimento da Escuta Ativa com os alunos seguiu os seguintes passos: o repertório foi apresentado aos alunos paulatinamente de forma que os mesmos aprendessem o conteúdo aplicado; em cada aula foi apresentado um gênero musical e por último a abordagem sobre o período musical escolhido; procurou-se despertar nos alunos o interesse e o senso crítico - interpretação das letras e identificação dos instrumentos musicais utilizados - ao escutar as músicas; em todos os gêneros musicais abordados nas aulas, os alunos escutaram a música por completo, em seguida abriu-se um espaço para comentários e debates sobre o estilo musical escolhido; depois escutaram a música mais duas vezes com intervenções que demonstravam alguns aspectos ainda não identificados pelos alunos; no final da aula pode-se avaliar o que os alunos compreenderam e as novas experiências musicais que os mesmos adquiriram.

De acordo com a análise feita dos resultados da pesquisa realizada com os alunos, cujo objetivo era descobrir as influências e experiências musicais dos mesmos, descobriu-se que o repertório que melhor adequou à turma foi: Sertanejo Universitário, Rock Nacional (anos 80), Blues e como contexto histórico o Período Barroco, com explicações sobre as características próprias do período e quais foram os principais compositores.

Abaixo segue a especificação de cada gênero e período musical escolhido para a atividade, elencado na forma como foi exposto em sala de aula para os alunos.

\section{Sertanejo Universitário}

De origem brasileira, é o resultado da mistura do estilo Sertanejo e o ritmo Arrocha voltado ao público jovem. Predominante em todas as regiões brasileiras por tratar em suas letras de assuntos do cotidiano e estórias de 
amor. Atualmente é considerada tendência musical e os instrumentos musicais mais utilizados são: violão, acordeom, bateria, contrabaixo, guitarra e percussão.

Os artistas que melhor representam esse gênero musical são: Fernando e Sorocaba, Victor \& Léo, Cezar Menotti \& Fabiano, Luan Santana, Gustavo Lima, entre outros.

A obra escolhida foi "Gaveta", da dupla Fernando \& Sorocaba (http://www.vagalume.com.br/fernando-esorocaba/gaveta.html).

A letra trata de forma abstrata sobre um relacionamento mal sucedido o qual a protagonista tenta esquecer sua desilusão amorosa tratada como arrogante e prepotente.

Mistura elementos comuns à realidade dos jovens e culturas do universo sertanejo, litorâneo e esportivo (futebol).

Os elementos musicais desta obra são característicos de um ritmo no violão acompanhado de sons suaves de sintetizador emulando sonoridade de cordas (violinos) e a voz principal acompanhada da "segunda voz", característica marcante de qualquer gênero sertanejo.

Uma curiosidade acerca desta obra é o videoclipe $^{i}$ de lançamento, o qual protagoniza uma desavença entre um casal jovem, aparentemente junto há muito tempo, com cenas que podem ir ao encontro de situações semelhantes no dia a dia de muitos casais.

\section{Rock Nacional (anos 80)}

Trata-se de um movimento da juventude urbana da época pós-ditadura. $\mathrm{Na}$ ocasião o país enfrentava esta transição e buscava amadurecimento

e autoconhecimento.

Foi basicamente influenciado pelo movimento Punk ${ }^{i i}$ do final dos anos 70, tanto em sonoridade quanto em ideologia. Mas também tinha intensa raiz dos anos anteriores da MPB.

A maioria das letras era em formas de protesto e conscientização, de estilo irreverente e intelectual, mudando para sempre a maneira de se ouvir e fazer rock no Brasil.

Sua maior difusão foi na cidade de Brasília, Rio de Janeiro e São Paulo, se popularizando como uma poderosa ferramenta de expressão e comunicação.

Alguns grupos musicais se destacaram nesse gênero, como Titãs, Legião Urbana, Os Paralamas do Sucesso, Ira!, Ultraje a Rigor, Engenheiros do Hawaii, Barão Vermelho, RPM, entre outros.

Os Instrumentos musicais mais utilizados são: guitarra, violão, teclado, bateria e contrabaixo.

A obra escolhida foi "Que país é este", da banda Legião Urbana (http://www.vagalume.com.br/legiaourbana/que-pais-e-esse.html).

A letra faz uma severa crítica ao sistema político brasileiro, enfatizando a 
corrupção, o atraso do desenvolvimento nacional e a desigualdade social.

Esta música desenvolve uma metáfora que propicia ao ouvinte fazer questionamentos sobre o tema e induz o pensamento crítico e questionador sobre os rumos nacionais.

A música é estruturada por uma introdução com um riff ${ }^{i i i}$ de contrabaixo, em contraponto com slides $^{i v}$ de guitarra distorcida e com efeito de eco; a guitarra acompanha a harmonia com acordes distorcidos e a bateria começa seu ritmo base; em seguida aparece o riff característico do arranjo, executado em um violão; a voz executa uma melodia marcante com excelente timbre e técnica, sem acompanhamento de outras vozes.

Uma Curiosidade observada é que a obra musical em questão foi proibida de ser transmitida em rádios, devido o teor de protesto em seu texto. A censura ainda permeava sobre o território nacional e seguiu ainda, por alguns anos, oprimindo a criação de artistas que quisessem protestar e questionar os líderes nacionais e suas condutas. Mais tarde se tornou parte do repertório das bandas "Os Paralamas do Sucesso" e "Capital Inicial".

\section{Blues}

De origem estadunidense, teve suas raízes nos cantos de lamentos dos escravos africanos imigrantes, os quais entoavam versos melodiosos enquanto executavam suas tarefas. Estes mesmos, após serem libertos, levaram estas raízes musicais às igrejas cristãs protestantes.

Deu-se, portanto, desta forma, a origem do Blues, que por sua vez se desenvolveu e evoluiu, contribuindo diretamente para o surgimento de todos os estilos chamados de música popular ocidental. Entre eles: jazz, rhythm and blues, rock and roll, country, soul music, música pop convencional, reggae, dance music ${ }^{v}$, entre outros.

A maioria das letras dessas canções era de cunho religioso ou estórias melancólicas. Com maior difusão foi em Chicago, Mississipi e Texas.

Os representantes mais conhecidos desse gênero são: Robert Johnson, B. B. King, Muddy Waters, John Lee Hooker, Stevie Ray Vaughan, John Mayer, entre outros.

Os instrumentos musicais mais utilizados são: guitarra, violão, piano, contrabaixo, gaita e bateria.

A obra escolhida foi "Pride And Joy", do cantor e guitarrista do Texas, Stevie Ray Vaughan (1954 - 1990) (http://www.vagalume.com.br/vaughanstevie-ray/pride-and-joy.html).

Por apresentar características de rhythm and blues, a letra fala de um feliz relacionamento de amor. Devido ao ritmo e sonoridade ser "alegre", o conceito de melancolia não combina com esta música, tendendo assim a um estilo definido como 
festivo, onde o autor declara seu amor à sua namorada.

Os Elementos musicais presentes nesta obra são: introdução com um riff de guitarra de sonoridade característica no blues e country; o contrabaixo e a bateria acompanham o desenvolvimento; a guitarra sempre se destaca, sendo amplamente explorada pelo arranjo do autor, contendo longos solos melodiosos; a voz é forte, primitiva e sem técnica, característica do estilo e cantada sem acompanhamento de outras vozes.

"Pride And Joy" foi a música de maior divulgação do álbum "Texas Flood", de Stevie Ray Vaughan, lançado em 1983. Disco este que resgatou o Blues, até então esquecido no meio musical, e o tornou destaque mundial novamente.

\section{Barroco}

O Barroco foi um movimento que envolveu todas as artes em suas concepções de estética e criação. Novas abordagens e padrões marcaram e influenciaram pra sempre o estilo de vida e os rumos de todas as manifestações artísticas.

Considera-se início entre o final do século XVI e meados do século XVIII, inicialmente na Itália, se expandindo a quase todos os países de cultura ocidental.

A característica mais marcante desse período foi o "exagero" nos detalhes e riqueza na construção das obras, abusando da criatividade e ousadia. “A palavra 'Barroco' é provavelmente de origem portuguesa, significando pérola ou jóia de formato irregular. De início, era usada para designar o estilo da arquitetura e da arte do século XVII, caracterizado pelo emprego excessivo de ornamentos.” (Roy Bennett, 1986).

Considera-se este movimento predominantemente de música "erudita", ou seja, se diferencia dos padrões estéticos e sonoros da música popular ocidental.

Maiores representantes desse período são: Claudio Monteverdi, Johann Sebastian Bach e Antonio Vivaldi.

Cravo, violino, violoncelo e flauta são os instrumentos musicais mais utilizados nas composições do Período Barroco.

A obra musical escolhida para a escuta direcionada foi “As Quatro Estações”, do compositor italiano Antonio Vivaldi (1678-1741). Essa música não foi apresentada aos alunos na íntegra, pois a mesma tem a duração de quarenta minutos e devido ao tempo disponibilizado para aula, optou-se por compilar, destacando os momentos principais da música.

Dividida em quatro movimentos justamente representando as quatro estações do ano, apresenta nuances e riqueza dinâmica, com texturas e sonoridades que remetem às características de cada estação.

Obra exclusivamente instrumental, porém sua construção estrutural e harmônica estimula a imaginação do ouvinte o elevando 
à interpretação e visualização destes quatro ciclos naturais. Melodias marcantes executadas em uníssono por um naipe de violinos permeiam todos os quatro movimentos. Existe o baixo contínuo executado pelo naipe de violoncelos. Outro naipe de violinos periodicamente se contrapõe à melodia principal, ocasionando $\mathrm{O}$ desenvolvimento harmônico.

Uma curiosidade acerca da obra apresentada aos alunos é que "As Quatro Estações" é a obra mais conhecida do compositor Antonio Vivaldi, o qual também era padre. Porém as maiorias das pessoas somente conhecem o início do primeiro movimento devido à sua marcante linha melódica.

\section{Conclusões e considerações}

Constatou-se um grande entusiasmo por parte dos alunos quanto à proposta e desenvolvimento da atividade. Este era exatamente o objetivo principal resultante desta prática: fomentar situações que ativem nos alunos a paixão pela arte musical.

Sempre haverá uma preocupação com informações, produção de conhecimento e aprendizado. Porém, na educação musical o foco inicial deve ser o desenvolvimento e o estímulo nos alunos à apreciação musical com qualidade, assim desenvolvendo a escuta ativa moral de forma incisiva e permanente na vida das pessoas.
Consideramos que a arte musical deve ser tratada, antes de qualquer procedimento, como entretenimento, o que eleva o aluno a classificar e elencar seus níveis de apreciação.

O objetivo maior desta metodologia de pesquisa foi oferecer meios de obter informações que norteiem esta prática em sala de aula dirigida pelo professor, com resultados relatados.

A juventude tende a ser influenciada pelos interesses da mídia e a pluralidade cultural está presente em nossa vida de forma dinâmica, resultado do acesso imediato a qualquer tipo de informação. Devido a estes fatores cabem a nós, educadores, o papel de mediadores destas informações e expositores dos elementos musicais qualitativos, para assim formar uma nova geração de ouvintes apreciadores com ferramentas ideológicas que possibilitem suas escolhas e filtrem seus interesses. Observa-se que a falta de interesse dos alunos por determinados estilos musicais ocorre em função da falta de acesso a estes estilos ou até mesmo, orientações históricas das músicas que possibilitem compreender o cotidiano de uma época que colaboraram na criação, divulgação e execução das mesmas. A Escuta Ativa Direcionada, é, portanto, uma ferramenta pedagógica na compreensão não somente da atividade musical, mas também dos aspectos históricos, sociológicos e culturais das diversas épocas de nossa sociedade. 


\section{Referências Bibliográficas}

BARBOSA, M. da G. da S. et al. Escuta Ativa e Compreensão Musical: relato de uma experiência de formação de platéia em Cruzeiro do Sul - AC. 2011. 102p.

Monografia (Curso de Licenciatura em Música a Distância) - Universidade de Brasília. Disponível em:

<http://bdm.unb.br/bitstream/10483/2797/1/2 011_MariaBarboza_JanioTeixeira_EmersonN ogueira_LuizOliveira.pdf>. Acesso em: 27 out. 2014.

\section{BENETT, R. Uma Breve História da}

Música. Tradução COSTA, M. T. R. Rio de Janeiro, Jorge Zahar Ed., 1986.

BRASIL. Lei no 9.394, de 20 de dezembro de 1996. Estabelece as Diretrizes e Bases da Educação Nacional.

BRASIL. Ministério da Educação e do Desporto. Parâmetros Curriculares Nacionais: Arte/ Secretaria de Educação Fundamental. Brasília: MEC/SEF, 1997.
GOULART, N. Ensino de música eleva desempenho escolar, diz estudo: Pesquisa pioneira conduzida pela Unifesp analisa comportamento de estudantes com idades entre 8 e 10 anos. Revista Veja, 27 fev. 2013. Disponível em:

<http://veja.abril.com.br/noticia/educacao/est udo-relaciona-ensino-de-musica-adesempenho-academico-e-habilidades-deleitura>. Acesso em: 01 nov. 2014.

\section{MOLINA, S. Níveis de Escuta de Uma} Obra Musical II. 2012. Disponível em: <http:www.cmozart.com.br/Artigo5.php>. Acesso em: 01 nov. 2014.

SILVA NETO. M. R. Estratégia para uma
escuta musical ativa: utilizando a
diversidade musical. 2012. 26 p. Trabalho de
Conclusão de Curso (Licenciatura em
Música) - Universidade de Brasília.
Disponível em:
<http://bdm.unb.br/bitstream/10483/4832/1/2
2012MoisesRibeirodaSilvaNeto.pdf>. Acesso
em: 01 nov. 2014.

\footnotetext{
${ }^{\text {i }}$ Filme dirigido e encenado por atores ou os próprios artistas, de roteiro em alusão ao tema da obra.

${ }^{i i}$ Movimento musical que faz críticas à sociedade. As músicas possuem um andamento rápido.

${ }^{\text {iii }}$ Progressão de acordes ou notas que são repetidas.

iv Técnica de ligado em instrumentos de cordas que "escorrega" de uma nota à outra.

${ }^{\mathrm{v}}$ Estilos musicais norte americanos.
} 